\title{
Nowe możliwości leczenia zaburzeń erekcji u mężczyzn z cukrzycą typu 2
}

\author{
New possibilities for treatment of erectile dysfunction \\ in men with type 2 diabetes
}

\section{STRESZCZENIE}

Wśród chorych z cukrzycą zaburzenia erekcji występują u ponad połowy pacjentów. Dysfunkcja seksualna może wynikać m.in. z zaburzeń metabolicznych, naczyniowych, neurologicznych, hormonalnych, psychogennych lub wiązać się ze stosowaną farmakoterapią innych zaburzeń. Wywiad w kierunku zaburzeń erekcji powinien być stałym elementem konsultacji diabetologicznej. Lekami pierwszego rzutu są inhibitory fosfodiesterazy 5 (PDE5). Najnowszym, wysoce selektywnym lekiem z tej grupy jest awanafil - lek o szybkim początku działania i wysokiej skuteczności u chorych z cukrzycą. (Diabet. Klin. 2015; 4, 4: 158-162)

Słowa kluczowe: cukrzyca, zaburzenia funkcji seksualnych, inhibitor fosfodiesterazy typu 5, awanafil

\section{ABSTRACT}

More than 50 percent of diabetes patients suffer from erectile dysfunction (ED). Sexual dysfunction may be due to metabolic, vascular, neurological, endocrine, psychological causes or be associated with side effects of pharmacotherapy. A history of erectile dysfunction should be a regular part of medical check-up. The first line treatment in majority of patients with ED are

Adres do korespondencji:

dr n. med. Roman Kuczerowski

Warszawski Uniwersytet Medyczny

e-mail: rkuczerowski@interia.pl

Diabetologia Kliniczna 2015, tom 4, 4, 158-162

DOI: 10.5603/DK.2015.0017

Nadesłano: 17.08.2015

Przyjęto do druku: 07.10.2015 phosphodiesterase 5 (PDE5) inhibitors. The new, highly selective medicine of this group is avanafil - a drug with rapid onset of action and high efficacy in patients with diabetes. (Diabet. Klin. 2015; 4, 4: 158-162)

Key words: diabetes mellitus, erectile dysfunction, phosphodiesterase 5 inhibitor, avanafil

\section{Wstęp}

Zaburzenia funkcji seksualnych u pacjentów z cukrzycą pojawiają się szczególnie często. Cukrzyca zwiększa 4-krotnie ryzyko zaburzeń erekcji, definiowanych jako utrzymująca się niezdolność do osiągnięcia i/lub podtrzymania wzwodu wystarczającego do odbycia stosunku seksualnego.

W Stanach Zjednoczonych wśród mężczyzn chorujących na cukrzycę w wieku powyżej 40 lat zaburzenia wzwodu występują u ponad połowy pacjentów, zaś całkowity brak erekcji u $10 \%$. W badaniach populacji polskiej obejmującej ponad 6,5 tys. pacjentów z cukrzycą zaburzenia erekcji występowały u 69,52\%. Czas trwania cukrzycy i wyrównanie metaboliczne wpływają na częstość występowania i stopień nasilenia dysfunkcji seksualnej. Zaburzenia erekcji mogą być jednym z pierwszych objawów cukrzycy typu 2. Wynika stąd praktyczny wniosek - u mężczyzn zgłaszających tę dolegliwość należy przeprowadzić diagnostykę w kierunku cukrzycy. Oprócz zaburzeń erekcji u pacjentów z cukrzycą częściej występują obniżenie libido, zaburzenia ejakulacji. Zaburzenia sfery seksualnej dotyczą także kobiet chorujących na cukrzycę. Polegają one na obniżonym libido, suchości pochwy, zaburzeniu orgazmu. Zaburzenia te pojawiają się częściej i w młodszym wieku niż u osób bez cukrzycy [1-4]. 


\section{Przyczyny zaburzeń erekcji}

W rozwoju zaburzeń erekcji u mężczyzn z cukrzycą rolę mogą odgrywać czynniki metaboliczne, naczyniowe, neurogenne, hormonalne, urologiczne, polekowe oraz psychogenne.

\section{Czynniki metaboliczne}

Zarówno krótkotrwałe epizody wysokich wartości glikemii, jak i przewlekła hiperglikemia należą do czynników metabolicznych odpowiedzialnych za zaburzenia potencji. Wpływ czynników metabolicznych ma charakter zarówno bezpośredni - i w tym wypadku odwracalny, jak i pośredni, sprzyjający rozwojowi angiopatii i neuropatii cukrzycowej. Udowodniono, że poprawa wyrównania metabolicznego wyrażająca się obniżeniem wartości glikemii oraz hemoglobiny glikowanej wiąże się ze zmniejszeniem nasilenia dysfunkcji seksualnej. Również inne składowe zespołu metabolicznego, takie jak otyłość czy hiperlipidemia, zwiększają ryzyko zaburzeń erekcji.

\section{Przyczyny naczyniowe}

Nadciśnienie tętnicze, występujące u ponad $50 \%$ osób z cukrzycą typu 2, jest istotnym dodatkowym czynnikiem ryzyka rozwoju zaburzeń funkcji seksualnych u mężczyzn. Zarówno stopień nadciśnienia tętniczego, jak i czas jego trwania odgrywają istotną rolę. Zwiększona częstość zaburzeń erekcji może wynikać ze stosowanej terapii hipotensyjnej z wykorzystaniem leków np. starszej generacji czy moczopędnych. Istotne nasilenie zaburzeń wzwodu może się wiązać z leczeniem tiazydami lub antagonistą aldosteronu - spironolaktonem. Nasilenie dysfunkcji seksualnej u mężczyzn, obserwowane $w$ trakcie terapii z zastosowaniem innych leków hipotensyjnych (np. inhibitorów konwertazy, blokerów kanałów wapniowych), może pojawić się w przypadku nadmiernego obniżenia ciśnienia tętniczego. Stosowanie $\beta$-blokerów wykazujących działania plejotropowe, np. nebiwololu, jest korzystniejsze u mężczyzn z zaburzeniami erekcji. Nebiwolol charakteryzuje się, poza bardzo wysoką selektywnością, dodatkowym działaniem zwiększającym uwalnianie tlenku azotu. Zaburzenia funkcji seksualnych należą także do wczesnych objawów powikłań sercowo-naczyniowych nadciśnienia tętniczego. Angiopatia może być obecna już w chwili rozpoznania cukrzycy. Retinopatia cukrzycowa występuje u 18-20\% osób ze świeżo zdiagnozowaną cukrzycą, sugerując co najmniej 5-letnie opóźnienie rozpoznania. Retinopatia cukrzycowa często kojarzy się z neuropatią. Może ona wynikać ze zmian mikroangiopatycznych dotyczących naczyń odżywczych (vasa nervorum). Zarówno mikro-, jak i makroangiopatia stanowią czynnik ryzyka zaburzeń funkcji seksualnych. Zmiany makroangiopatyczne mogą rozwijać się u osób z niezdiagnozowaną cukrzycą, przebiegającą w sposób utajony i w stanie przedcukrzycowym. $W$ przebiegu makroangiopatii zaburzenia erekcji mogą wynikać z zaburzeń przepływu krwi, np. w tętnicach biodrowych, udowych, tętnicy sromowej, jak również z manifestacji klinicznych makroangiopatii - choroby niedokrwiennej serca, niewydolności serca. Pierwszymi objawami cukrzycy typu 2 mogą być zaburzenia wzwodu u mężczyzn, a nie poliuria, polidypsja, utrata masy ciała czy też somnolencja [5-7].

\section{Przyczyny neurogenne}

Układ autonomiczny odgrywa kluczową rolę w regulacji wzwodu. $Z$ tego powodu jedną z głównych przyczyn zaburzeń erekcji jest neuropatia autonomiczna. Może ona się rozwijać po wielu latach niewyrównanej cukrzycy. Do czynników ryzyka należą m.in. hiperglikemia, częste hipoglikemie, podeszły wiek, płeć męska, otyłość, nadużywanie alkoholu, palenie tytoniu oraz czynniki genetyczne. Neuropatia autonomiczna dotyczy zarówno układu współczulnego, jak i przywspółczulnego, a zaburzenia erekcji należą do manifestacji neuropatii autonomicznej obok takich objawów, jak tachykardia spoczynkowa, hipotonia ortostatyczna, skłonność do arytmii, zaburzenia potliwości, zaburzenia motoryki przewodu pokarmowego (atonia pęcherzyka żółciowego, nocne biegunki, zaburzenia perystaltyki przełyku i żołądka), atonia pęcherza moczowego, utrata odczuwania hipoglikemii. Za zaburzenia erekcji w głównej mierze odpowiada neuropatia układu przywspółczulnego, natomiast neuropatia układu współczulnego może doprowadzić do zaburzeń ejakulacji [8].

\section{Przyczyny hormonalne}

Za zaburzenia funkcji seksualnych u osób z cukrzycą może być odpowiedzialny zespół niedoboru testosteronu (TDS, testosterone deficiency syndrome). Definiuje się go jako niedobór testosteronu objawiający się zmniejszeniem libido i potencji, stałym zmęczeniem, pogorszeniem jakości snu, nerwowością, uderzeniami gorąca, zmniejszeniem masy mięśniowej. W badaniach biochemicznych charakteryzuje go obniżone stężenie testosteronu z podwyższonym stężeniem gonadotropin w surowicy. Za wartości charakteryzujące TDS przyjmuje się stężenie testosteronu poniżej $6,94 \mathrm{nmol} / \mathrm{l}(2 \mathrm{ng} / \mathrm{ml})$, zaś frakcji wolnej testosteronu poniżej $0,31 \mathrm{nmol} / \mathrm{l}$ (89 pg/ml). O stężeniu wolnego testosteronu decyduje również stężenie globuliny wiążącej hormony płciowe (SHBG, sex hormone binding globulin). Jest to ważne, ponieważ postacią czynną biologicznie jest tylko wolny cholesterol. Stężenie SGBG wzrasta z wiekiem $z$ reguły około $1 \%$ rocznie od 40 . roku życia. Na stę- 
żenie SHBG wpływa również stan insulinooporności. W wielu badaniach nie stwierdzono jednak korelacji pomiędzy objawami klinicznymi hipogonadyzmu a stężeniem testosteronu całkowitego. Wskazaniem do terapii substytucyjnej testosteronem jest występowanie objawów z towarzyszącym stężeniem całkowitego testosteronu poniżej $8 \mathrm{mmol} / \mathrm{l}$. Można rozważyć próbę leczenia testosteronem osób z objawami klinicznymi TDS oraz stężeniem całkowitego testosteronu pomiędzy 8-12 mmol/l. Pomocne może być również wyznaczenie wskaźnika niedoboru testosteronu u mężczyzn ze stężeniem całkowitego testosteronu rzędu 3,5-4 ng/ml, uwzględniające stężenie gonadotropiny LH (hormon luteinizujący). Wartości $\mathrm{T} / \mathrm{LH} \leq 1$ (testosteron $\mathrm{ng} / \mathrm{ml}$, LH IU/ml) mogą stanowić wskazanie do zastosowania terapii testosteronem. Bezwzględnym przeciwwskazaniem do hormonoterapii jest rak prostaty i rak sutka, policytemia oraz znaczny rozrost gruczołu krokowego utrudniający oddawanie moczu.

Do relatywnie częstych przyczyn zaburzeń wzwodu należy hiperprolaktynemia. Może ona odpowiadać za 3-8\% przypadków zaburzeń potencji u mężczyzn. Podwyższone stężenia prolaktyny (PRL) może być uwarunkowane obecnością gruczolaka przysadki (prolaktinoma). Inną przyczyną pochodzenia przysadkowego jest obecności gruczolaka nieczynnego hormonalnie uciskającego szypułę i powodującego zniesienie hamującego wpływu dopaminy na sekrecję PRL. U mężczyzn z prolaktinoma zaburzenia potencji występują w ponad 90\% przypadków. Poza zaburzeniami wzwodu hiperprolaktynemia powoduje obniżenie libido, może stanowić przyczynę ginekomastii, mlekotoku, oligospermii. Rozpoznanie opiera się na stwierdzeniu zaburzenia erekcji, wykazaniu stężenia prolaktyny ponad $150 \mathrm{ng} / \mathrm{ml}$ oraz ujawnieniu gruczolaka w badaniu obrazowym (badaniem z wyboru jest rezonans magnetyczny). U mężczyzny z hiperprolaktynemią trzeba rozważyć inne przyczyny zaburzeń endokrynologicznych. Podwyższone stężenie PRL może mieć charakter wtórny. Do przyczyn należy niedoczynność tarczycy (podwyższone stężenie TRH w pierwotniej niedoczynności tarczycy, np. w przebiegu choroby Hashimoto, pobudza sekrecję zarówno TSH, jak i prolaktyny), niewydolność nerek (wzrost PRL wynika z zaburzonej eliminacji prolaktyny), marskość wątroby. Istotny jest także wpływ stosowanych leków upośledzające sekrecję lub działanie dopaminy, np. metoklopramid, neuroleptyki. W przypadku wysokich wartości PRL, którym nie towarzyszą objawy kliniczne hiperprolaktynemii, jako przyczynę warto uwzględnić makroprolaktynemię. Makroprolaktyna to wielkocząsteczkowa prolaktyna połączona z przeciwciałem klasy lgG anty-PRL. Wywiera ona niewielki efekt biologiczny, wpływa na wyniki oznaczeń laboratoryjnych.
U mężczyzn z prolaktinoma postępowaniem z wyboru jest wieloletnie leczenie farmakologiczne agonistami dopaminy, np. bromokryptyną, chinagolidem lub kabergoliną. W przypadku braku skuteczności leczenia farmakologicznego (co jest zjawiskiem rzadkim) lub złej tolerancji terapii alternatywą jest zabieg neurochirurgiczny z resekcją gruczolaka. Niestety rozpoznanie prolaktinoma u mężczyzn - w przeciwieństwie do kobiet - ma charakter opóźniony i diagnozowaną zmianą jest makrogruczolak (guz o wymiarach $10 \mathrm{~mm}$ i więcej).

Kolejną przyczyną zaburzeń erekcji może być hiperkortyzolemia zarówno endogenna, jak i w przebiegu steroidoterapii. Mechanizm tego zjawiska polega na hamującym wpływie sekrecji LH przez kortyzol. Powoduje to zmniejszenie syntezy testosteronu w jądrach, co prowadzi do obniżenia libido i zaburzeń wzwodu. Podejrzewając hiperkortyzolemię endogenną, polecanym testem diagnostycznym jest test hamowania z $1 \mathrm{mg}$ deksametazonu. Poranna kortyzolemia we krwi poniżej $50 \mathrm{nmol} / \mathrm{l}(1,8 \mu \mathrm{g} / \mathrm{dl}) \mathrm{np} .9 \mathrm{godzin}$ po podaniu doustnym deksametazonu ma charakter wykluczający.

Dysfunkcja seksualna u mężczyzn z cukrzycą może wynikać z współistniejącej niedoczynności tarczycy. Jej najczęstszą przyczyną jest autoimmunologiczne zapalenie tarczycy. Wczesne rozpoznanie choroby Hashimoto i zastosowanie właściwej dawki substytucyjnej L-tyroksyny przynosi istotną poprawę [9-11].

U pacjentów z cukrzycą dwukrotnie częściej niż u osób zdrowych występują epizody depresji lub przewlekły stan subdepresyjny. Obniżony nastrój sam w sobie może być przyczyną spadku libido, zaburzeń erekcji. Zaburzenie funkcji seksualnych może także wynikać z koniecznego leczenia przeciwdepresyjnego, $\mathrm{np}$. w trakcie przyjmowania leków z grupy inhibitorów wychwytu zwrotnego serotoniny czy też trójpierścieniowych leków przeciwdepresyjnych. Także stosowanie neuroleptyków, takich jak pochodne fenotiazyny, tioksantenu i butyrofenonu, może być odpowiedzialne za występowanie zaburzeń potencji.

Nadużywanie alkoholu i palenie tytoniu zwiększa ryzyko zaburzeń potencji u mężczyzn chorujących na cukrzycę.

\section{Diagnostyka}

Większość pacjentów z cukrzycą nie zgłasza spontanicznie problemów życia intymnego i oczekuje pytań ze strony lekarza. W diagnostyce zaburzeń potencji w ramach wizyty diabetologicznej pomocne byłoby rutynowe stosowanie przynajmniej skróconej wersji kwestionariusza The International Index of Erectile Function (IIEF). Obejmuje on 5 pytań:

1. Jak ocenia Pan swoją pewność, że mógłby Pan osiągnąć i utrzymać erekcję? 
2. Jeśli erekcja wystąpiła w wyniku stymulacji seksualnej, jak często była nasilona na tyle, że umożliwiała odbycie stosunku płciowego?

3. Jak często podczas stosunku płciowego był Pan w stanie utrzymać erekcję?

4. Jak trudno było Panu utrzymać erekcję do zakończenia stosunku płciowego?

5. Jeśli podejmował Pan stosunek płciowy, jak często dostarczył on Panu zadowolenie?

W diagnostyce zaburzeń erekcji kluczowe znaczenie ma badanie układu krążenia i ocena zaburzeń neurologicznych. Na współistniejącą przyczynę dysfunkcji sfery seksualnej mogą wskazywać wyniki badań laboratoryjnych, np. cechy uszkodzenia wątroby, niewydolności nerek, chorób gruczołu krokowego, niedoboru testosteronu, nadmiaru prolaktyny, złego wyrównania metabolicznego $[12,13]$.

\section{Terapia}

Istotna jest eliminacja czynników ryzyka, leczenie obejmujące zarówno psychoterapię, jak i leczenie farmakologiczne. Warunkiem jest dobre wyrównanie metaboliczne - osiągnięcie stężeń glukozy zbliżonych do normy (zarówno na czczo, jak i po posiłkach), przy jednoczesnym unikaniu niedocukrzeń. U pacjentów z cukrzycą zastosowanie znalazły preparaty apomorfiny, wstrzyknięcia do ciał jamistych papaweryny, alprostadilu, systemy próżniowe, implanty. Zasadniczym postępem w leczeniu zaburzeń erekcji stało się wprowadzenie tzw. inhibitorów fosfodiesterazy 5, takich jak awanafil, sildenafil, tadalafil, wardenafil. Leki te wykazują wysoką skuteczność u pacjentów z cukrzycą.

\section{Awanafil - najnowszy lek z grupy inhibitorów fosfodiesterazy 5}

Zahamowanie aktywności fosfodiesterazy typu 5 (PDE5, phosphodiesterase type 5) przez awanafil powoduje zwiększenie stężenia cyklicznego guanozyno-5'-monofosforanu (cGMP) w ciałach jamistych prącia. Powoduje to lokalne uwolnienie tlenku azotu i w następstwie rozkurcz mięśni gładkich wzrost napływu krwi i na skutek tego erekcję. Zjawiska te zachodzą wyłącznie w warunkach stymulacji seksualnej.

Awanafil jest wysoce selektywnym inhibitorem PDE5. Wobec innych fosfodiesteraz jego powinowactwo jest znacznie mniejsze. Ma to istotne znaczenie kliniczne.

Awanafil blisko 20 tys. razy silniej hamuje PDE5 niż PDE3. PDE3 występuje w sercu i naczyniach krwionośnych, odgrywając istotną rolę dla czynności inotropowej serca. W porównaniu z inhibicją PDE5 wpływ awanafilu na PDE6 jest 100 razy mniejszy, na PDE4, PDE8 i PDE10 - 1000 razy mniejszy,
PDE2 i PDE7 - 5000 razy mniejszy, PDE1, PDE3, PDE9 i PDE11 - 10000 razy mniejszy.

Awanafil dobrze i szybko wchłania się po podaniu doustnym, osiągając maksymalne stężenie po 30-45 minutach. Posiłki bogate w tłuszcze opóźniają wchłanianie leku. W 99\% wiąże się on z białkami osocza. Metabolizowany jest głównie w wątrobie przy udziale CYP3A4 oraz w mniejszym stopniu CYP2C9. Metabolit awanafilu M4, stanowiący około 1/4 metabolitów, również wykazuje czynność biologiczną. Jest 5-krotnie słabszym od awanafilu, wysoce selektywnym inhibitorem PDE5. Czas półtrwania awanafilu wynosi 6-17 godzin. Metabolity awanafilu ulegają wydaleniu przez przewód pokarmowy, a w mniejszym stopniu (21\%) przez nerki.

Lek jest stosowany w dawkach 50, 100, 200 mg. Nie ma potrzeby dostosowania dawki u osób w wieku podeszłym ani osób z cukrzycą.

U osób z łagodnym lub umiarkowanym zaburzeniem czynności nerek [szacunkowy współczynnik filtracji kłębuszkowej (eGFR, estimated glomerular filtration rate) $>$ 30] nie ma konieczności dostosowania dawki. U pacjentów z umiarkowanym uszkodzeniem wątroby wskazane jest rozpoczęcie terapii od najmniejszej skutecznej dawki. Spożywanie alkoholu nie jest przeciwwskazane u osób przyjmujących awanafil. Warto jednak poinformować pacjentów o możliwości wystąpienia objawowego niedociśnienia tętniczego.

Przeciwwskazane jest stosowanie inhibitorów PDE5 u osób po przebytym udarze, ostrym zespole wieńcowym w ciągu ostatnich 6 miesięcy, z hipotensją < 90/50 mm Hg, a także niekontrolowanym nadciśnieniem tętniczym > 170/100 mm Hg. Do innych przeciwwskazań należą m.in. zastoinowa niewydolność serca (klasa II-IV wg New York Heart Association), ciężka niewydolność wątroby (klasa C w skali Childa i Pugha), niewydolność nerek charakteryzująca się eGFR $<30 \mathrm{ml} / \mathrm{min}$. Podobnie jak innych inhibitorów PDE5 awanafilu nie wolno łączyć z nitratami ze względu na ryzyko ciężkiej hipotensji. Nie należy łączyć awanafilu również z lekami hamującymi CYP3A4, takimi jak klarytromycyna, itrakonazol, ketokonazol, rytonawir, atazanawir, indynawir, nefazodon, nelfinawir, sakwinawir, telitromycyna.

Jednoczesne stosowanie awanafilu z lekami takimi jak erytromycyna, flukonazol, werapamil, aprepitant nie jest przeciwwskazane z zaleceniem nieprzekraczania dawki jednorazowej 100 mg i przyjęcia kolejnej dawki po upływie co najmniej 48 godzin.

Stosowanie inhibitorów PDE5 wymaga szczególnej ostrożności u osób z anatomicznymi deformacjami prącia oraz chorobami predysponującymi do wystąpienia priapizmu (anemia sierpowatokrwinkowa, szpiczak mnogi, białaczka). 
Ze względu na potencjalne hamowanie CYP3A4 przez substancje zawarte w soku grejpfrutowym nie zaleca się jego spożywania w ciągu 24 godzin przed przyjęciem awanafilu.

Awanafil wykazuje wysoką skuteczność, poprawiając funkcje seksualne u pacjentów z cukrzycą, a nawet u pacjentów po prostatektomii. Swoje korzystne działanie rozwija już po 10-15 minutach od przyjęcia doustnego. Jego działanie związane jest nierozerwalnie ze stymulacją seksualną. Korzystny wpływ utrzymujący się ponad 6 godzin umożliwia spontaniczną aktywność seksualną. Możliwość przyjmowania awanafilu z posiłkiem zwiększa komfort pacjenta [14-24].

\section{Podsumowanie}

Zaburzenia sfery seksualnej u osób z cukrzycą są częste, ale niestety nie zawsze rozpoznawane przez lekarza diabetologa. Wywiad w kierunku tych zaburzeń powinien stanowić rutynowy element konsultacji lekarskiej. Wczesne rozpoznawanie i diagnostyka różnicowa przyczyn dysfunkcji seksualnej mają kluczowe znaczenia dla skuteczności leczenia. Najczęściej stosowane leczenie farmakologiczne $z$ wykorzystaniem inhibitorów fosfodiesterazy 5 wiąże się z poprawą funkcji seksualnych u chorych z cukrzycą zarówno typu 1 , jak i typu 2. Pojawienie się nowego leku z tej grupy o szybkim działaniu, wysokiej skuteczności i wyższym profilu bezpieczeństwa - awanafilu stwarza nowe możliwości poprawy jakości życia u chorych z cukrzycą.

\section{PIŚMIENNICTWO}

1. Dęmbe K., Jasik M., Niebisz A., Karnafel W. Wpływ niektórych leków na występowanie zaburzeń erekcji u pacjentów z cukrzycą. Seksuologia Polska 2010; 8: 20-25.

2. Lew-Starowicz Z., Skrzypulec V. Podstawy seksuologii. PZWL, Warszawa 2010

3. Dęmbe K., Jasik M., Stawicki S., Karnafel W. Patogeneza i częstość zaburzeń erekcji u chorych na cukrzycę. Seksuologia Polska 2004; 2: 2.

4. Selvin E., Burnett A.L., Platz E.A. Prevalence and risk factors for erectile dysfunction in the US. AM J. Med. 2007;120, 2: 151-157.

5. Ma R., Tong P. Erectile dysfunction in men with diabetes - an early warning for heart disease. Diabetes Voice 2008; 53: 25-27.

6. Fonseca V., Sefted A., Denne J. Impact of diabetes mellitus on the severity of erectile dysfunction and response to treatment; analysis of data from tadanafil clinical trials. Diabetologia 2004; 47: 1914-1923.

7. Musicki B., Burnett A. Endothelial dysfunction in diabetic erectile dysfunction. International Journal of Impotence Research 2007; 19: 129-138.

8. Moczulski D. (red.) Diabetologia, Wielka Interna. Medical Tribune Polska, Warszawa 2010; 161-162.

9. Rabijewski M. Postępy w rozpoznawaniu i leczeniu zespołu niedoboru testosteronu. Postępy Nauk Medycznych 2008; XXI: 165-170.

10. Kapor D., Aldred H., Clark S. i wsp. Clinical and biochemical assessment of hypogonadism in men with type 2 diabetes. Diabetes Care 2007; 30: 911-917.

11. Zgliczyński W. (red.) Endokrynologia, Wielka Interna. Medical Tribune Polska, Warszawa 2012; tom I: 65-68.

12. Dęmbe K., Karnafel W. Rozpoznawanie i leczenie zaburzeń erekcji u pacjentów z cukrzycą. Medycyna Metaboliczna 2011; XV: 75-78.

13. Rosen R.C., Cappelleri J.C., Smith M.D., Lipsky J., Peña B.M. Development and evaluation of an abridged, 5-item version of the International Index of Erectile Function (IIEF-5) as a diagnostic too for erectile dysfunction. Int. J. Impot. Res. 1999; 11: 319-326.

14. Charakterystyka Produktu Leczniczego Spedra ${ }^{\circledR}$

15. Puchalski B., Szymański F.M. Awanafil - nowy lek w terapii zaburzeń erekcji. Seksuologia Polska 2013; 11: 65-67.

16. Kyle J.A., Brown D.A., Hill J.K. Avanafil for erectile dysfunction. Ann. Pharmacother. 2013;47: 1312-1320.

17. Belkoff L.H., McCullough A., Goldstein I. i wsp. An open-label, long-term evaluation of the safety, efficacy and tolerability of avanafil in male patients with mild to severe erectile dysfunction. Int. J. Clin. Pract. 2013; 67: 333-341

18. Goldstein I., Jones L.A., Belkoff L.H. i wsp. Avanafil for the treatment of erectile dysfunction: a multicenter, randomized, double-blind study in men with diabetes mellitus. Mayo Clinic Proceedings 2012; 87: 843-852.

19. Goldstein I., McCullough A.R., Jones L.A. i wsp. A randomized, double-blind, placebo-controlled evaluation of the safety and efficacy of avanafil in subjects with erectile dysfunction. Journal of Sexual Medicine 2012; 9: 1122-1133.

20. Mulhall J.P., Burnett A.L., Wang R. i wsp. A phase 3, placebo controlled study of the safety and efficacy of avanafil for the treatment of erectile dysfunction after nerve sparing radical prostatectomy. Journal of Urology 2013; 189: 2229-2236.

21. Zhao C., Kim S.W., Yang D.Y. i wsp. Efficacy and safety of avanafil for treating erectile dysfunction: results of a multicentre, randomized, double-blind, placebo-controlled trial. BJU International 2012; 110: $1801-1806$.

22. Kedia G.T., Ückert S., Assadi-Pour F. i wsp. Avanafil for the treatment of erectile dysfunction: initial data and clinical key properties. Ther. Adv. Urol. 2013; 5: 35-41.

23. Hellstrom W.J., Kaminetsky J., Belkoff L.H. i wsp. Efficacy of Avanafil 15 Minutes after Dosing in Men with Erectile Dysfunction: A Randomized, Double-Blind, Placebo Controlled Study. J. Urol. 2015; 194, 2: 485-492.

24. Zalecenia kliniczne dotyczące postępowania u chorych na cukrzycę 2015. Diabetologia Kliniczna 2015; 4 (supl. A). 